\title{
Latent provisions for building information modeling (BIM) contracts: a social network analysis approach
}

Article

Accepted Version

Fan, S.-L., Chong, H.-Y., Liao, P.-C. and Lee, C.-Y. (2019) Latent provisions for building information modeling (BIM) contracts: a social network analysis approach. KSCE Journal of Civil Engineering, 23 (4). pp. 1427-1435. ISSN 1976-3808 doi: https://doi.org/10.1007/s12205-019-0064-8 Available at https://centaur.reading.ac.uk/87575/

It is advisable to refer to the publisher's version if you intend to cite from the work. See Guidance on citing.

Published version at: https://link.springer.com/article/10.1007\%2Fs12205-019-0064-8

To link to this article DOI: http://dx.doi.org/10.1007/s12205-019-0064-8

Publisher: Korean Society of Civil Engineers

All outputs in CentAUR are protected by Intellectual Property Rights law, including copyright law. Copyright and IPR is retained by the creators or other copyright holders. Terms and conditions for use of this material are defined in the End User Agreement.

www.reading.ac.uk/centaur 
Central Archive at the University of Reading

Reading's research outputs online 


\section{Latent Provisions for Building Information Modeling (BIM) Contracts: A}

\section{Social Network Analysis Approach}

\section{Abstract}

The effective adoption and use of Building Information Modeling (BIM) require appropriate contract design to fairly allocate the contracting parties' rights and responsibilities. Several standards for BIM protocols and contracts have been developed for the industry. However, the awareness and the use of these are rather limited, leading to unclear provisions in BIM contracts. Therefore, the research aims to identify the influential legal aspects that serve as the latent contract provisions in BIM contracts. A questionnaire survey was conducted to survey experts and active BIM users in construction projects. The data were analyzed using social network analysis (SNA) by assuming interdependent relationships among various the legal aspects in BIM contacts. The key legal aspects associated with BIM contracts pertain to the roles and responsibilities of the project participants. The results also reveal that data security is

\footnotetext{
**** Director of Research Development Center of Construction Law, Director of Taiwan-Malaysia Project Management and Digital Technology Centre; Associate Professor of Dept. of Civil Engineering, Tamkang University, No. 151, Ying-Chuan Road, Tamsui, Taipei County, Taiwan (E-mail: fansuling@hotmail.com)

** Senior Lecturer, School of Built Environment, Curtin University, Perth, Australia (E-mail: heap-yih.chong@curtin.edu.au)

* Associate Professor, Department of Construction Management, Tsinghua University, Beijing, China (Corresponding Author, Email: pinchao@tsinghua.edu.cn)

${ }^{* * *}$ Lecturer, School of Built Environment, University of Reading Malaysia, Iskandar Puteri, Johor, Malaysia (E-mail: celine.lee@reading.edu.my); Ph.D. Candidate, School of Built Environment, Curtin University, Perth, Australia (cenying.lee@postgrad.curtin.edu.au)
} 
the center of all latent legal aspects in the contracts. The study provides significant new insights into clarifying the required contract provisions in BIM contracts.

Keywords: BIM, legal aspects, contract provisions, contract administration

\section{Introduction}

Building information modeling (BIM) has been widely accepted in the architecture, engineering, construction, and operation (AECO) industry. However, most construction professionals are still unaware of the legal implications arising from BIM adoption. (Lowe and Muncey, 2009; Chew and Riley, 2013). Although several BIM protocols and contracts have been developed such as Joint Contracts Tribunal Public Sector Supplement (JCT, 2011), Document E203 TM -2013 - BIM and Digital Data Exhibit (AIA, 2013), ConsensusDocs 301-Building Information Modeling addendum (ConsensusDocs, 2013), AEC BIM Protocol (AEC, 2012), CIC BIM Protocol (CIC, 2013) and Complex Construction Contracts (CPC, 2013), the actual use of the protocols remains low (Al-Shammari, 2014). Previous related works mainly focused on the identification of potential BIM's legal risks (Hsu et al., 2015), legal implications in BIM implementation (Olatunji, 2011; Arensman and Ozbek, 2012; Eadie et al., 2015), adverse legal consequences in BIM contracts (Joyce and Houghton, 2014; Ussing et al, 2016), BIM's contractual arrangements (Kuiper and Holzer, 2013) intellectual property rights for BIM's copyright and ownership (Fan 2013) and a preliminary contractual framework for BIM-enabled projects (Chong et al., 2017). These studies showed that research into BIM contracts and the related legal aspects are still at a preliminary stage of development. It is vital to extend the previous research and make clear the important legal aspects which must be considered when devising BIM contracts. 
The aims of this research is to identify the influential legal aspects that serve as the latent contract provisions in BIM contracts. A questionnaire survey method was adopted to collect the empirical data from BIM active users and experts in Taiwan due to the popularity of BIM in that area (Chien et al., 2014). Subsequently, the data were analyzed using social network analysis (SNA). SNA is an effective tool for investigating complex networks that involve the interdependence of actors in social structures and non-social structure analysis (Lee et al., 2018). This method was adopted to identify the important legal aspects by assuming the interdependency relationships and flows among the legal aspects (nodes). The study would offer insightful references to practitioners on the important legal aspects to be used as contract provisions when designing BIM contracts.

\section{Legal Aspects and Contract Provisions}

$\mathrm{BIM}$ is an emerging technology in the building sector. However, the management of BIM practice is rather challenging and unstructured. It triggers numerous legal issues throughout the project lifecycle. An effective contract administration is one of the keys to regulating the new BIM practice via the written contract provisions. The contract provisions are effectively used to govern the legal issues and enforce necessary procedures required in BIM-enabled projects. Hence, it should identify and clarify the important legal aspects of BIM practices. Following a thorough literature review, the related legal aspects can be classified into three main categories, namely, (a) contract structure and policy, (b) contractual relationships and obligations, and (c) BIM model and security. 
BIM's contract structure and policy are used to govern the digitalized and collaborative

attributes. The existing BIM contract protocols provide new perspectives in governing project stakeholders; but there are still unclear policies to accommodate the changed project requirements (Redmond et. al., 2010). A different legal framework is required to clarify the procurement and contracting methodologies (Kuiper and Holzer, 2013). A popular legal framework has been initiated and promoted in the industry for BIM enabled-projects, which is called Integrated Project Delivery (IPD) (BuildingSMART-Australasia, 2012). However, IPD is not the only procurement that suits the BIM practice as different working cultures and the maturity of BIM use should be taken into account when determining an appropriate framework (Chong et al. 2016). Furthermore, IPD contracts are generally prepared in an ad hoc and complicated manner, which might not be generalized for all types of projects (Smith, 2014). This might be the reason for this procurement system or legal framework being unpopular in BIM-enabled projects. Consequently, certain legal aspects need to be considered to cope with this situation.

\subsection{Contractual relationships and obligations}

The development of a BIM model is a joint effort by several parties. In a common practice, a BIM execution plan will explain the details of the necessary checklist and standards for the project implementation. Unfortunately, this document generally does not form part of the contract (Hardin and McCool, 2015). The unclear roles and responsibilities give rise to legal liabilities (McAdam, 2010), including pure economic loss (Simonian and Korman, 2010). Hence, the contractual relationships need to be clarified especially for the key stakeholders (including the BIM manager), which will help to regulate the required responsibilities or functions in the BIM Execution Plan (Lowe and Muncey, 2009). This situation could then 
trigger another legal question on the need for additional insurance coverage throughout the development of BIM model (Enegbuma and Ali, 2011).

Besides, the standard of care needs to make clear for the project stakeholders when the liabilities and obligations have been regulated in the contract, (Hsieh et al., 2012). The common doctrines, namely, privity of contract and the Spearin doctrine can be referred and used to govern the stakeholders' duties. For example, a designer may not be able to claim the lack of privity of contract for his or her defense, especially under a collaborative system (Simoniam and Korman, 2010). As for the Spearin doctrine, it can be used by contractors as a legal defense to an employer's claim of nonconforming works (Barthet, 2010).

\subsection{BIM model and security}

One of the keys to BIM success is its digitalized data. The BIM information is digitalized and parameterized, such that the information can be easily extracted and reused either in whole or in part (Fan, 2014). Therefore, it raises a new problem about how the business knowledge can be protected. The security and privacy issues should not be ignored (Mahamadu et al., 2013). A common quick-response code (QR-Code) has been successfully integrated with BIM for optimizing the BIM model's information flow (Lorenzo et al., 2014). It can be used to prevent any infringements or copyrights issues related to the drawings and documents. Furthermore, a data-exchange plan is required to avoid transferring any unnecessary or incorrect information from the BIM model (Greenwood et al., 2010). The data-exchange plan should also address common interoperability issues; even though the Industry Foundation Classes (IFC) data modeling format has been developed as an open and neutral data format for the data exchange for BIM models (Steel et al., 2012).

Apart from that, a third party may incur an infringement claim from the model. It is advised that to make clear the intellectual property rights at the outset of the model 
117 Addendum and AIA Document E202 envisage that each party should own his/her rights as per the personal contribution. It also needs to comply with local statutory law or regulations in relation to data privacy and security (Fan, 2014). Therefore, all digital data should be well-kept and controlled. In addition, indemnity should be provided to protect the client's interests in the BIM model.

\section{Research Methodology}

None of the previous studies has considered the interdependent relationships among the key legal aspects of BIM. Most of the SNA-related studies, particularly in construction research, were qualitatively defined the strength of nodes (e.g. risks, stakeholders, etc.). This study used SNA to identify latent contract provisions based on the interdependent relationships measured by the covariance of expert opinions on each legal aspect. The steps of analyzing survey method was selected to obtain the primary data matrix, and (c) visualizations of association network. Consequently, a structured questionnaire

\subsection{Identification of legal aspects}

We relied on the existing measurement scales of the key legal aspects for the questionnaire design, for which the legal aspects have been validated in prior research (Chong et al., 2017). The questionnaire was organized into two sections, namely, Section A which was used to investigate the background of the respondents, and Section B which was used to examine the levels of agreement on the identified thirty-four legal aspects (A1 to A34) and the appropriateness of the legal aspects of BIM contracts. The measurement items A1, A2, A3, A4, A15, and A16 were excluded in the questions pertaining to the appropriateness of the legal 
aspects of BIM contracts as these were the legal issues associated with BIM contracts. The

142 five-point Likert scale, ranging from 1 (representing a zero of the trait; e.g. strongly disagree) to 5 (representing a perfectly positive assessment of the trait; e.g., strongly agree) was

144 conducted by representing the points in weighting with values of $-2,-1,0,1$, and 2 respectively 145 in the analysis. Table I lists the measurement items of the legal aspects (Chong et al., 2017).

Table I Key legal aspects for BIM-enabled projects

Code

Aspect \#1

A1

A2

A3

A4

A5

A6

A7

A8

\section{Legal Aspects}

\section{Contract Structure and Policy}

A specific standard form of contract is necessary to include the extent of all works and requirements of BIM; or

Scope and requirements of BIM are sufficiently covered using an addendum.

Scope and requirements of BIM should not be mandated with legal consequences; or

The contract document should include digital data and information.

In case of any discrepancies, two-dimensional (2D) drawings shall prevail over three-dimensional (3D) drawings; or

In case of any discrepancies, three-dimensional (3D) drawings with more details of the BIM model shall prevail over two-dimensional (2D) drawings;

Cost/payment of BIM should be charged based on a pre-determined proportion of the overall project cost; or Cost/payment of BIM should be charged based on the types of development, models, and functions required for the project; or 

on the work done; or completion and its functions required in the project. BIM model development. projects, such as IPD, partnering, etc.

The cost of developing the model, penalty, and rewards involved, if any, should be clarified earlier.

\section{Aspect \#2 Contractual Relationships and Obligations}

A new role of BIM Manager should be engaged in the project. be specified in the contract.

The contract should stipulate the BIM's goals and quality audit for different stages of BIM model development.

The contractual relationship among the owner, designers, and contractors should be clearly specified and linked to the project. the design team. Such loss/damage should be recovered by the injured party or third party. responsibilities for developing the BIM model. 
The Spearin doctrine should be applied and upheld. The contractor should not be liable for the loss or damage because of insufficient information that he received or followed. The designers should be responsible for the negligence towards the third party irrespective of Privity of Contract.

The contractor cannot make a claim from the design errors made by the designers which include pure economic loss. Standard of care should be applied and upheld by all parties who develop or use the BIM Model.

Additional insurance is necessary to cover all risks and liabilities involved with BIM models, software, and hardware.

\section{Aspect \#3 $\quad \underline{\text { BIM Model and Security }}$}

A QR-Code should be used to prevent copyright infringement issues on the drawings and documents.

To prevent issues of interoperability, a BIM model should be developed before the project development stages, and a construction-ready BIM model should be created before the construction stage. model.

The authorized user can use, access and reproduce the model if permission has been sought from the copyright owner. Each party owns all the rights to its own contribution if the model is designed and contributed to by a team. usage and data integrity. 
A31 Certain constraints should be imposed to hinder data loss and protect privacy.

A32 The data providers (designers or contractors) should be liable for the data included in the model.

A33 The party who hosts the model should include the use and access, recordkeeping, warranty and preservation of the model for the agreed duration.

A34 The owner should be indemnified because of data errors or technical issues arising from the use of BIM tools and software in the project.

\subsection{Development of association matrix}

Any relationships between a pair of legal aspects should be pre-defined. Agenda-setting theory is referred, which is the ability of the news media to influence the salience of topics on the public agenda (McCombs and Reynolds, 2002). By referring to that theory, Guo et al. (2012) proposed the network agenda setting model (NASM), they asserted that information on the news or various kinds of media deliver a set of provisions or attributes and make them salient in the public's mind. This model was adopted in research areas of business communication (Meijer and Kleinnijenhuis, 2006), interpersonal communication (Vu and Gehrau, 2010), advertising (Buzan and Buzan, 1996), and crime (Lowry et al., 2003). Since NASM used co-existence as the indicator of interconnections among various provisions, 
similarly, we used the covariance of evaluation on various legal aspects to be the level of their interdependencies. We assumed the covariance among the responses to the legal aspects as the input of SNA.

We utilized the absolute value of the Pearson product-moment correlation coefficient (PPMCC) derived from the responses as the indicator of the levels of interdependency among any pairs of legal aspects. This mimics the network-like structure regarding the associations of BIM related legal aspects in the minds of a group of people. The PPMCC $\left(\rho_{v_{i}, v_{j}}\right)$ illustrates the linear dependence between two variables $v_{i}$ and $v_{j}$ as shown by Eq. (1):

$$
\rho_{v_{i}, v_{j}}=\frac{\operatorname{cov}\left(v_{i}, v_{j}\right)}{\sigma_{v_{i}} \sigma_{v_{j}}}
$$

where cov represents the covariance and $\sigma_{v_{i}}$ stands for the deviation in $v_{i}$.

According to the responses, we regard the larger the $\left|\rho_{v_{i}, v_{j}}\right|$ as the stronger the interconnections between the pair of variables $v_{i}$ and $v_{j}$.

Significant statistical relationships among two legal aspects may exist, however, the generic associations among content of the clauses may not reflect by covariance among responses. Therefore, a focus group consisting of five corporate and project managers was used to discuss whether the relationships and strength are either counterintuitive to practices. All of them have had more than 10 years of experience in BIM-enabled projects. The research background was first introduced at the beginning of the focus group meeting and a questionand-answer session was held to clarify the understanding of each pair of relationships. The statistically significant relationships of the dyads (pairs of legal aspects) were then further screened according to the following questions: 1) should any legal aspects of the dyad be a prerequisite or supplementary condition? 2) do the correlations among legal aspects reflect 


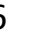

8

actual practices? The above-mentioned questions were fully addressed by the focus group based on a consensus decision-making process.

\subsection{Visualization of association network}

\subsubsection{Network index}

Density: Density (G) stands for the density value of network G, as given by Eq. 2. Here, $\mathrm{K}$ is the existing related pairs and $\mathrm{N}$ is the number of total variable items. The network density ranges from 0 to 1 . A high density means that variable pairs are consistently coherent in the minds of the respondents.

Density $(\mathrm{G})=\mathrm{K} /(\mathrm{N}(\mathrm{N}-1))$

Cohesion: Cohesion $(\mathrm{G})$ refers to the condensed value of network $\mathrm{G}$, as given by Eq. 3 . AdjM is the adjacency matrix of network G. Z represents the average shortest-path between points. AdjM2 is the number of connecting lines while $\mathrm{Z}$ is in the network. $\mathrm{N}$ is the total number of variable items. As the cohesion increases, so too does the complexity of the variable relationship.

4

$$
\text { Cohesion }(\mathrm{G})=\left(\sum \operatorname{AdjMz}\right) /(\mathrm{N}(\mathrm{N}-1)
$$

6

\subsubsection{Point/line index}

Degree Centrality: This refers to the number of edges directly attached to a node. It is used to analyze the importance of a node from its leadership and influence positions within a network (Doloi, 2012). Nevertheless, degree centrality may not necessarily be a proxy for a node's leadership position (Solis et al., 2013). Hence, other measures must be used to determine 
the importance and the saliency of the legal aspects. Degree centrality is expressed as in Eq. (4):

$$
C_{D}\left(p_{i}\right)=\sum_{k=1}^{N} a\left(p_{i}, p_{k}\right)
$$

where, $a\left(p_{i}, p_{k}\right)=1$, if there is a direct tie between $p_{i}$ and $p_{k}$ dan $\mathrm{i} \neq \mathrm{k}$.

Betweenness Centrality: This shows the effect of a given point/line between two points or lines. A node with a high betweenness centrality value has some control over the network as other nodes depend on that node to connect to each other (Chowdhury et al., 2011). The betweenness centrality of the ith variable, $v_{i}$, is expressed by Eq. (5).

$$
\mathrm{g}\left(v_{i}\right)=\sum_{v_{i} \neq v_{j} \neq v_{k}} \frac{\sigma_{v_{j} v_{k}}\left(v_{i}\right)}{\sigma_{v_{j} v_{k}}}
$$

where $\sigma_{v_{j} v_{k}}$ is the total of the shortest path from variable $v_{j}$ to variable $v_{k}$ and $\sigma_{v_{j} v_{k}}\left(v_{i}\right)$ represents the number of that path through $v_{i}$. This measures the gatekeeper role of $v_{i}$. Brokerage considers the variable partitions. Using Gould \& Fernandez's brokerage, one can measure every triad and role of each variable in that triad for a specific partition vector. In a contractual network, the partitions are categorized in various categories. These categories are identified by measuring the number of times of each variable is numbered in the brokerage relationships such as coordinator, gatekeeper, representative, itinerant, liaison.

Coordinator: If a variable $v_{i}$ is correlated with another two variables $v_{j}$ and $v_{k}$ in the same partition, then add one coordinator score to variable $v_{i}$. If either one of the $v_{j}$ and $v_{k}$ is associated with $v_{i}$, add one gatekeeper or representative score to $v_{i}$. In both $v_{j}$ and $v_{k}$ are in the same partition but different from $v_{i}$, and both are associated with $v_{i}$, then add 1 itinerant score to $v_{i}$. Lastly, if $v_{j}, v_{k}$, and $v_{i}$ are in different partitions then add one liaison score to $v_{i}$. 

the sum of the centralities of a node's neighbors (Estrada and Rodríguez-Velázquez, 2005). It assigns relative scores to all the nodes in the network based on the legal aspects that connections to high-scoring nodes contribute more to the score of the node in question than equal connections to low-scoring nodes. Eigenvector centrality is also used to identify the importance of a practice by determining the feasibility of the said practice because of other practices (Pishdad-Bozorgi et al., 2016) and the key trades (Wambeke et al., 2014). In procurement networks, the actor with the highest eigenvector centrality score is considered the most important member affecting the main pattern of the distances of all actors (Chowdhury et al., 2011). Hence, eigenvector centrality is also considered as an important measure to identify the influence of a legal aspect of the network. For a given graph, G: $=(\mathrm{V}, \mathrm{E})$ with $|\mathrm{V}|$ number of vertices let $A=(a v, t)$ be the adjacent matrix, i.e. $a v, t=1$ if vertex $v$ is linked to vertex $t$, and $a v, t=0$ otherwise. The relative centrality score of vertex v can be defined by Eq. (6).

$$
x_{v}=\frac{1}{\lambda} \sum_{t \in M(v)} x_{t}=\frac{1}{\lambda} \sum_{t \in G} a_{v, t} x_{t}
$$

where $\mathrm{M}(\mathrm{v})$ is a set of neighbors of $\mathrm{v}$ and $\lambda$ is a constant. higher values of density cohesion, degree centrality, betweenness centrality, brokerage, and eigenvector centrality should be managed (reviewed or revised) with higher attention.

4. Results and Analysis Thirty-six valid questionnaires were returned and used for the data analysis. This sample size is sufficient when applying the central limit theorem based on its means value that approaches the normal distribution. Table II shows that most of the respondents were aged 
259 from within 41 to $60(56 \%)$; some were below $40(36 \%)$, and few were above $60(8 \%)$. Their 260 occupations included architects (33\%), consultants (28\%), contractors (22\%), educators (17\%), 261 developers (3\%), and government employers (3\%). Most of the respondents had attained a 262 post-graduate level of education (61\%) and had more than ten years working experience in the 263 construction industry (67\%).

Table II Demographic information of subjects

\begin{tabular}{|l|c|l|c|}
\hline Age & $\begin{array}{l}\text { Subjects in the } \\
\text { sample }(\%)\end{array}$ & Occupation & $\begin{array}{l}\text { Subjects in the } \\
\text { sample (\%) }\end{array}$ \\
\hline Below 30 & 5.5 & Architects & 33 \\
\hline 31 to 40 & 30.5 & Consultants & 28 \\
\hline 41 to 50 & 36 & Contractors & 22 \\
\hline 51 to 60 & 20 & Developers & 3 \\
\hline Above 61 & 8 & Educators & 17 \\
\hline & & $\begin{array}{l}\text { Government } \\
\text { or } \\
\text { government- } \\
\text { owned } \\
\text { corporation } \\
\text { employers }\end{array}$ & 3 \\
\hline
\end{tabular}

265

Subsequently, SNA was used to analyze the questionnaire data. Table III lists the evenly distributed variables across the legal aspects.

Table III: Results of network analysis

\begin{tabular}{|l|c|}
\hline Legal Aspects & $\begin{array}{c}\text { Number of } \\
\text { Variables }\end{array}$ \\
\hline Contract Structure and Policy & 13 \\
\hline Contractual Relationships and Obligations & 11 \\
\hline BIM Model and Security & 10 \\
\hline
\end{tabular}


Fig. 1 illustrates the interdependent network. The relationships were measured by PPMCC $(\mathrm{p}<0.05)$. The size of the nodes represents the degree centrality, while the shape and color indicate the type of legal variables $($ red circle $=$ structure and policy, blue square $=$ relationship and obligations, and black triangle $=$ model, and security). The thickness of the edges represents the level of strengths interlinked two legal aspects. As shown in Table IV, the density of the risk network equals 0.47 ; $\mathrm{SD}=0.1$ and therefore this network is regarded as being very dense. If the density is between 0 and 0.25 , the network is regarded as having a low density (Wellman, 1976). Network centralization accounted for only $13.03 \%$. It shows that there is low centralization among the legal aspects with greater centrifugal forces and smaller centripetal forces. On average, these variables are connected by 2.19 walks. This means that any two legal aspects can only be connected through two or more legal aspects. Table IV lists the interdependent network metrics.

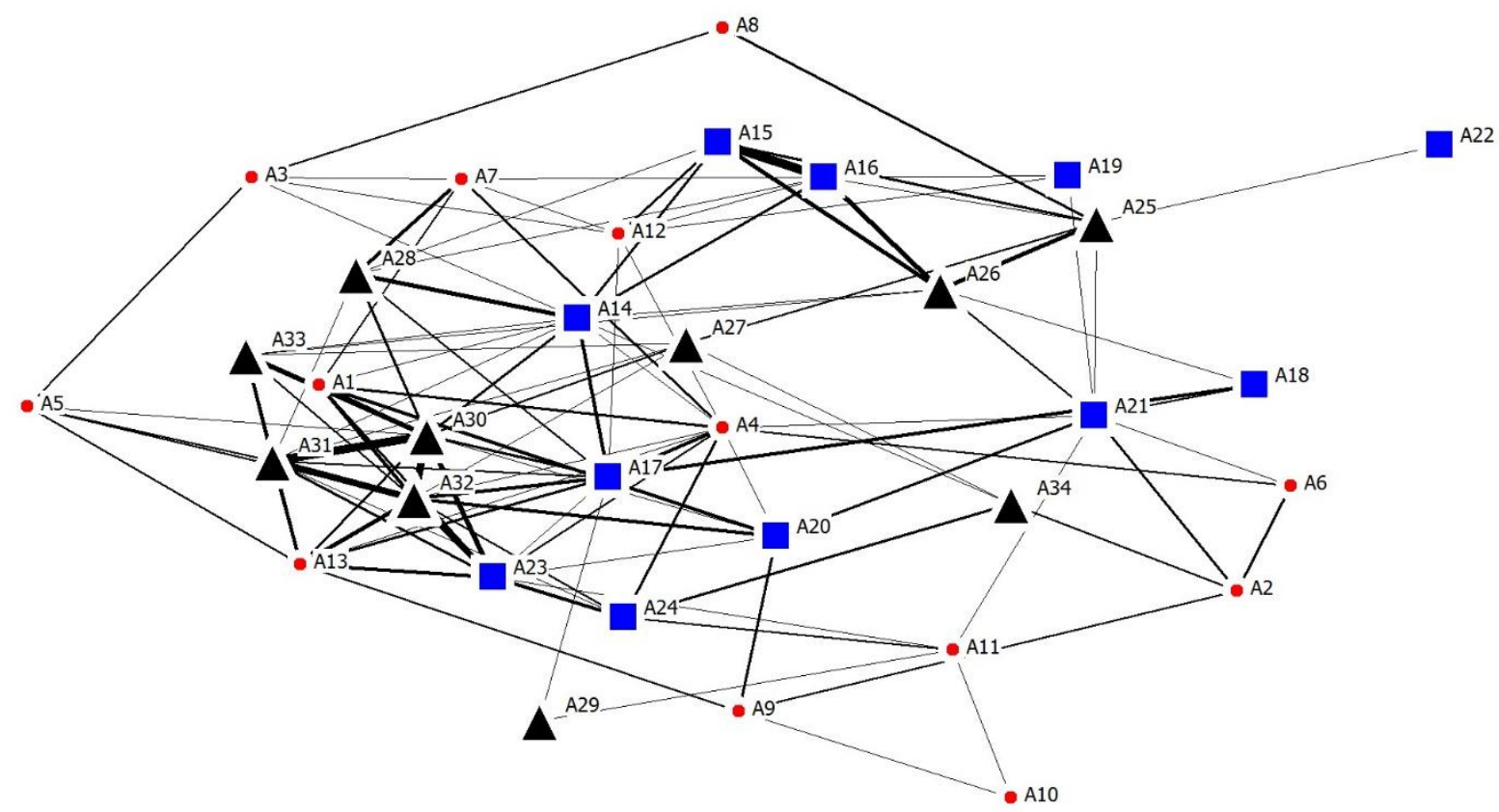

Fig.1: Association network visualized with degree centrality 


\begin{tabular}{|c|c|}
\hline Network Metrics & Value \\
\hline Density & 0.47 \\
\hline Cohesion & 0.54 \\
\hline Centralization & $13.03 \%$ \\
\hline Steps & 2.19 walks \\
\hline
\end{tabular}

290

From the dimensions of the network structure, the density value represents an average level of possible relationships in the network. This shows the possibility of some provisions interrelating with each other. The network has a cohesion value of 0.54 , which is larger than the density value. There are strong direct interrelationships (indicated by the thickness of the ties) among the legal aspects in relation to BIM model and security. These legal aspects include security of digital data usage and its integrity should be protected (A30), restrictions should be imposed to reduce the loss of data and its privacy (A31), data providers should be responsible for any data provided by them and which is included in the BIM model (A32), and the host of the model should be responsible to use, access, maintain, warrant, and retain the model for the agreed duration (A33). For contractual relationships and obligations, the robust links are found among these three legal aspects such as, roles and scope of works for parties involved (A15) and goals of BIM and its quality checks in various stages of development (A16) should be defined in the contract. To prevent interoperability issues in the post-construction stage, the BIM model should be developed ahead of all the development stages, particularly before the construction stage (A26). The strong interrelationships among the above legal aspects indicate that they are dependent on each other. The design of BIM contracts would not be complete without linking these legal aspects. 
Figure 1 also shows that A30, A32, A31, A17, A14, A4, and A23 have the greatest degree

centrality, whereby these variables are assumed to be linked with most of the other legal aspects. Based on the dimensions of the individual legal aspects, the degree centrality measures the legal aspects that have many ties to other aspects. In terms of contract structure, the aspect which has a high degree centrality include BIM data should be included as part of the contract (A4). For contractual responsibilities, a new BIM manager (A14), and the definition and the interrelationship among project participants involved in BIM are also had a high degree centrality. Additionally, the parties who use or contribute to the BIM model, and who should also apply the standard of care when handling the model (A23), is another influential legal aspect. For the BIM model and security, the impactful aspects include the security of digital data usage and the protection of integrity (A30), certain control mechanisms should be adopted to mitigate the loss of data and privacy (A31) and data providers should be responsible for the data provided by them in the BIM model (A32). Although the centrality degree measure captures the number of "interactions," it does not, however, capture the capability of their of legal aspects on others. information between variables. By comparing with Fig.2 and Table IV, A14, A21, and A25 have a high betweenness centrality, indicating they should be considered as carrying the most critical information among all the legal aspects. Although A25 does not have high degree centrality, it has high betweenness centrality. It plays an important role in information dependency. Legal aspects with a high betweenness centrality are regarded as being influential 
within the association network as once they are removed from the network (broker and coordinator), they will disrupt connections between other legal aspects because they lie on the largest number of paths taken by messages. In terms of contract structure and policy, digital 337 data should form part of the contract document (A4), the development of guidelines should 338 follow the BIM model development (A11), and the cost of model development such as penalty 339 and rewards should be clarified in the contract (A13). For contractual relationships and 340 obligations, the significant legal aspects which are a new role of BIM manager should be 341 appointed (A14), and the relationships between the project participants should be defined 342 (A17). When devising the contracts, the issues pertaining to the designers should be responsible 343 for the third party's negligence regardless of the privity of contracts (A21). The absence of this 344 legal aspect will reduce the confidence level of using BIM and develop ambiguity among contracting parties regarding the responsibilities involved. The legal aspects of the BIM model and security have a lower betweenness centrality value relative to the two legal aspects but

347 they are still considered important as in the absence of these aspects as they will de-facilitate 348 the smooth implementation of BIM. These aspects, including the QR-code, should be used to 349 prevent infringements (A25), while the designers own the copyright model (A27), the security 350 of digital data should be protected (A27), and the data providers should be responsible for the data provided to them in the BIM model (A32). 


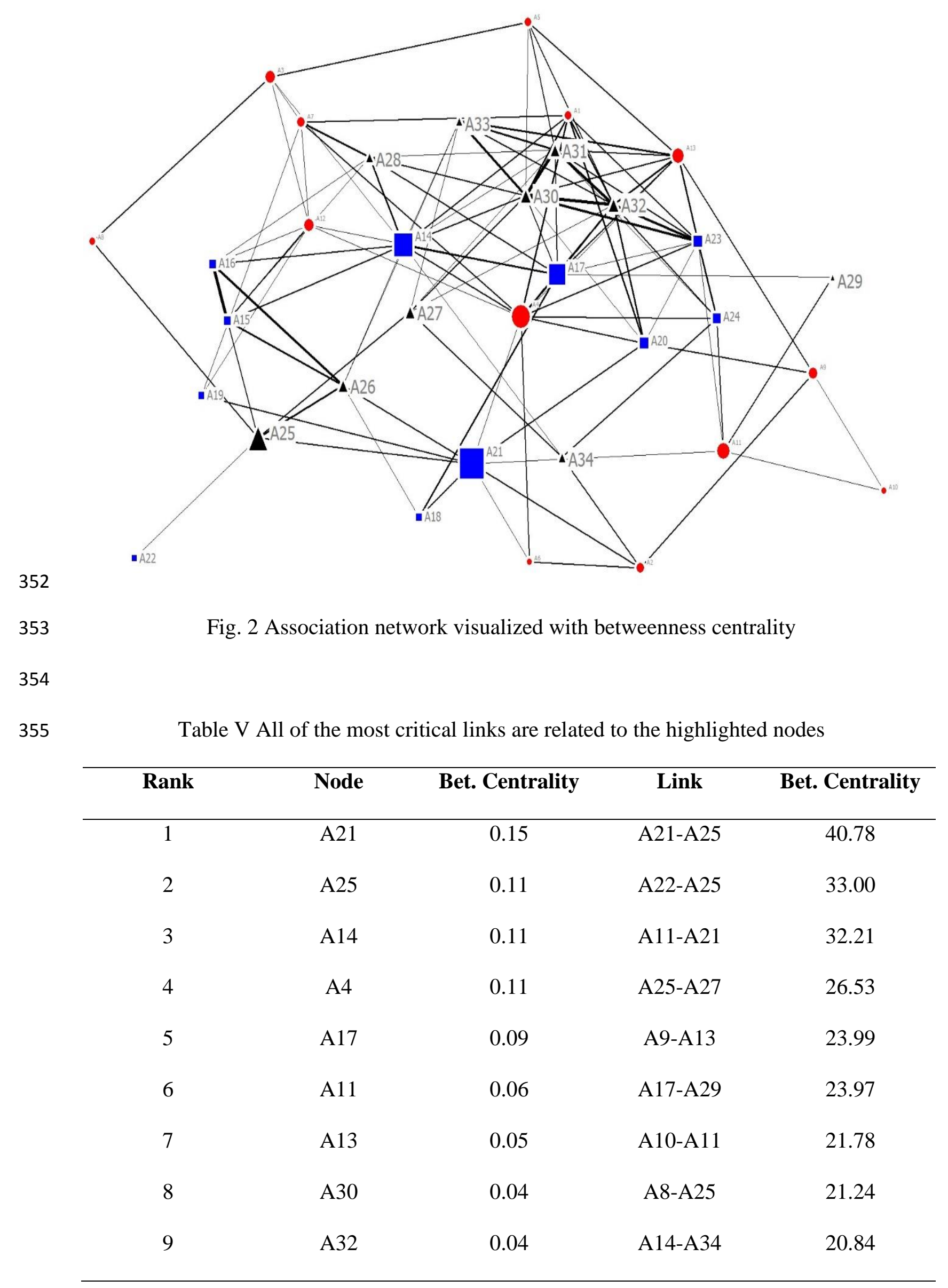




\begin{tabular}{lllll}
\hline 10 & A27 & 0.04 & A19-A21 & 20.41
\end{tabular}

\subsection{Eigenvector Centrality}

Eigenvector centrality is used to determine the most influential legal clauses in terms of their power by considering the power of their neighbors. The most central actors can be determined (i.e. those which are the least far removed from the others) in terms of the "global" or "overall" structure of the network. In Fig. 3, the A30, A31, A32, A17, and A23 variables have a high eigenvector centrality, indicating that these legal aspects are more peripheral. They also connect to most of the aspects, which have a higher degree centrality. These aspects include the protection of the security of digital data (A30), the implementation of certain restrictions to reduce data loss (A31), and data providers being responsible for incorporating the data into the BIM model (A32).

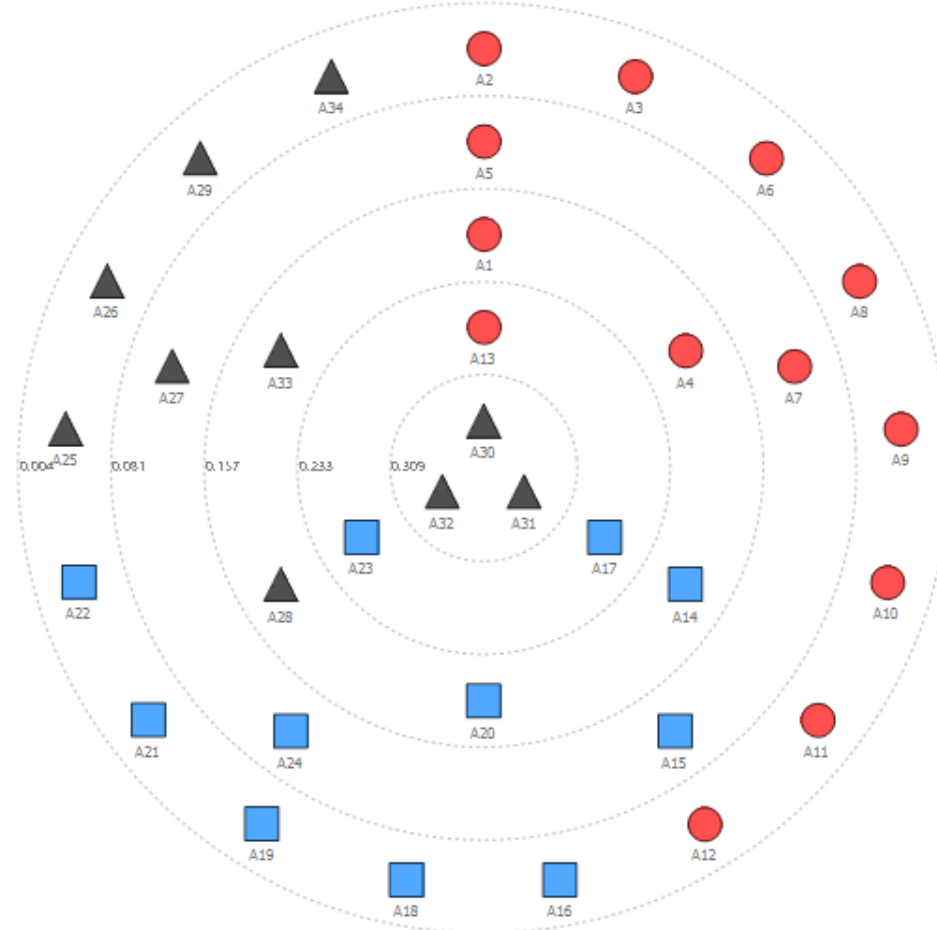

Fig. 3 Eigenvector centrality 


\section{Discussion and conclusions}

The present study successfully utilized SNA to identify those influential legal aspects which will be used or modified as contract provisions in BIM contracts. The association network is developed and observed in terms of its structure as well as the status of each legal aspect. From a network perspective, the relationships among the three different legal aspects are rather dense and cohesive. The variables affecting data security have a higher degree of centrality, betweenness centrality, and eigenvector centrality. For instance, data should be protected (A30) and data providers should be liable for the inserted data (A32). In addition, the relationships among various stakeholders, their responsibilities, and punitive measures should be considered accordingly. For example, a BIM manager's role and the protection of intellectual property are critical "hinges," which interconnect various legal aspects.

In addition, some legal issues and requirements should be further considered when drafting BIM contracts. For instance, copyright issues are critical to maintaining the confidence of the designers, while maintaining the high-quality data entered as part of the process (Manderson et al., 2015), including confidential information about trade secrets and intellectual property allocation in a collaborative environment (Azhar, Khalfan, and Masqsood, 2012; Olsen and Taylor, 2010; Porwal and Hewage, 2013). Nevertheless, we found that this legal aspect remains critical in terms of the "hinges," which should be considered to protect data security. In other words, this study casts light on how these legal aspects interconnect with each other. Given that BIM-enabled projects may evolve and impose a legal liability on construction professionals, professional liability should be considered as a supporting mechanism that enables the operability of a contract (Khosrowshahi and Arayici, 2012; Olsen and Taylor, 2010; Rezgui et al., 2013). In the present study, the A34 variable (namely, indemnity being required to protect the client's interests in the event of any errors or technical issues caused by tools or software used in the project) addresses this topic, however, it does 
not seem "critical" to the development of the contract. The reader should interpret this result carefully. Although the research has identified the "centrality" of legal aspects, those legal aspects that are non-central are not necessarily unimportant. Instead, these non-central legal aspects can serve as mechanisms that support the design of central legal aspects.

In conclusion, the present study has revealed insightful implications into significant legal aspects or contract provisions that need to be included in BIM contracts. These contribute to innovative contracts through the realization of the current strict and rigid contractual governance from conventional transaction cost economics theory. New adjustments to the contract functions can be considered, in which the coordination and contingency adaptability should be incorporated into the latent contract provisions, which will enhance the collaboration and relationships of the contracting parties in BIM-enabled projects. Consequently, this contracting approach can drive and improve the overall project performance. However, certain limitations must be considered. The application of legal doctrines such as the Spearin doctrine may not apply in Commonwealth countries. The research findings were based on Taiwanese legal formations. Hence, certain adjustments are required to enable application in countries with legal doctrines that differ from that in Taiwan. Moreover, different procurement strategies such as collaboration project delivery methods shall be distinguished from conventional procurement methods like design-bid-build and design-and-build when designing BIM contracts.

\section{Acknowledgments}

This research was supported by the National Natural Science Foundation of China (No. 51878382 and No. 51578317) as well as the Taiwan-Malaysia Project Management and Digital Technology Centre and Research Development Center of Construction Law, Tamkang University. 


\section{References}

422

423

424

425

426

427

428

429

430

431

432

433

434

435

436

437

438

439

440

441

442

443

444

AEC (2012). AEC (UK) BIM PROTOCOL. AEC (UK) CAD \& BIM Standards Site, UK. Available at: https://aecuk.files.wordpress.com/2012/09/aecukbimprotocol-v2-0.pdf [3rd January 2018]

AIA (2013). AIA Document E203TM-2013. The American Institute of Architects, USA. Available at: http://www.aia.org/aiaucmp/groups/aia/documents/pdf/aiab099084.pdf [3rd January 2018]

Al-Shammari, M.A. (2014). "An appraisal of the protocol that was published by the construction industry council (CIC) to facilitate the use of building information modelling (BIM) on projects.” Procs 30th Annual ARCOM Conference, Association of Researchers in Construction Management, pp.623-632.

Arensman, D. B. and Ozbek, M. E. (2012). "Building information modeling and potential legal issues.” International Journal of Construction Education and Research, Vol. 8, No. 2, pp. 146-156, DOI: $10.1080 / 15578771.2011 .617808$

Barthet, A. (2010). A Contractor's Defense: The Spearin Doctrine. Available at: http://www.thelienzone.com/a-contractors-defense-the-spearin-doctrine/ [3rd January 2018]

BuildingSMART-Australasia 2012. Strategy: A strategy for the focused adoption of building information modelling and related digital technologies and processes for the Australian built environment sector. National Building Information Modelling Initiative. Vol.1

Buzan, T. and Buzan, B. (1996). The Mind Map Book: How to Use Radiant Thinking to Maximize Your Brain's Untapped Potential. Plume, USA.

CIC (2013). CIC BIM Protocol. Construction Industry Council, United Kingdom. Available at: http://cic.org.uk/download.php?f=the-bim-protocol.pdf [3rd January 2018] 
Chew, A., and Riley, M. (2013). "What is Going On with BIM? The Way to 6D." The International Construction Law Review, pp.253-265.

Chong HY, Lopez R, Wang J, Wang X and Zhao Z. A. (2016). "Comparative Analysis on the Adoption and Use of BIM in Road Infrastructure Projects." Journal of Management in Engineering. DOI: 10.1061/(ASCE)ME.1943-5479.0000460.

Chong, H. Y., Fan, S. L., Sutrisna, M., Hsieh, S. H. and Tsai, C. M. (2017). "Preliminary Contractual Framework for BIM-Enabled Projects.” Journal of Construction Engineering and Management, 143(7), pp. 1-8.

Chowdhury, A.N., Chen, P.H. and Tiong, R.L. (2011). "Analysing the structure of publicprivate partnership projects using network theory." Construction Management and Economics, Vol. 29, No.3, pp.247-260.

Chien, K. F., Wu, Z. H. and Huang, S. C. 2014. "Identifying and assessing critical risk factors for BIM projects: Empirical study.” Automation in Construction, Vol. 45, pp. 1-15.

ConsensusDocs (2013). ConsensusDocs 301: Building Information Modelling (BIM) Addendum. ConsensusDocs, US.

CPC (2013). Contract for Complex Projects. The Chartered Institute of Building, United Kingdom. Available at: http://www.ciob.org/media-centre/news/world\%e2\%80\%99sfirst-time-management-contract-complex-projects-published-ciob [3rd January 2018].

Doloi, H. (2012). “Assessing stakeholders' influence on social performance of infrastructure projects.” Facilities, Vol. 30, No.11/12, pp.531-550.

Eadie, R., McLernon, T. and Patton, A. (2015). “An investigation into the legal issues relating to Building Information Modelling (BIM)." Proceedings of RICS COBRA AUBEA 2015.

Enegbuma, W. I. and Ali, K. N. (2011). “A Preliminary Study on Building Information Modeling (BIM) Implementation in Malaysia." 3rd International Postgraduate Conference on Infrastructure and Environment (IPCIE2011), Hong Kong. 
470 Estrada, E. and Rodriguez-Velazquez, J.A. (2005). "Subgraph centrality in complex networks." Phys. Review, Vol.71, No. 5, 056103.

472

Fan, S.L. (2014). "Intellectual Property Rights in Building Information Modelling application in Taiwan.” Journal of Construction Engineering Management, Vol. 43, No. 3. DOI: 10.1061/(ASCE)CO.1943-7862.0000808

Greenwood, D., Lewis, S. and Lockley, S., (2010). "Contractual Issues in the Total Use of Building Information Modelling." Proceeding: W113 - Special Track 18th CIB World Building Congress May 2010 Salford, UK, pp. 363-371.

Guo, L., Vu, H. T. and McCombs, M. (2012). "An Expanded Perspective on Agenda-Setting Effects. Exploring the third level of agenda setting." Revista de Comunicación, Vol.11, pp.51-68.

Hardin, B. and McCool, D. 2015. BIM and construction management: proven tools, methods, and workflows. John Wiley \& Sons.

Hsieh, T.Y., Yeh, F. and Hsu, K.M. (2012). "Legal Risks Incurred under the Application of BIM in Taiwan." 14th International Conference on Computing in Civil and Building Engineering, Mscow, Russia.

Hsu, K. M., Hsieh, T. Y. and Chen, J. H. 2015. Legal risks incurred under the application of BIM in Taiwan. Proceedings of the Institution of Civil Engineers-Forensic Engineering, Vol. 168, No. 3, pp.127-133.

JCT (2011). Public Sector Supplement: Fair Payment, Transparency and Building Information Modelling. Available at: http://corporate.jctltd.co.uk/wp-content/uploads/2016/03/JCTPublic-Sector-Supplement-Dec20111.pdf $\square$ 3rd January $2018 \square$

Joyce, R. and Houghton, D. 2014. Briefing: Building Information Modelling and the Law. Proceedings of the Institution of Civil Engineers Management, Procurement and Law, Vol.167, No. 3, pp.114-116. 
Kuiper, I. and Holzer, D. (2013). "Rethinking the contractual context for Building Information Modelling (BIM) in the Australian built environment industry." Australasian Journal of Construction Economics and Building, Vol 13, No. 4, pp.1-17.

Lee, C. Y., Chong, H. Y., Liao, P. C. and Wang, X. (2018). Critical Review of Social Network Analysis Applications in Complex Project Management. Journal of Management in Engineering, Vol. 34, No. 2, 04017061.

Lorenzo, T. M., Benedetta, B., Manuele, C. and Davide, T. 2014. "BIM and QR-code. A synergic application in construction site management." Procedia Engineering, Vol.85, pp. $520-528$.

Lowe, R. H. and Muncey, J. M. (2009). "The ConsensusDOCS 301 BIM Addendum." Construction Lawyer, Vol.29, No.1, pp.1-9.

Lowry, D.T., Nio, T.C.J. and Leitner, D.W., 2003. "Setting the public fear agenda: A longitudinal analysis of network TV crime reporting, public perceptions of crime, and FBI crime statistics.” Journal of Communication, Vol. 53, No. 1, pp.61-73.

Mahamadu, A.M., Mahdjoubi,L. and Booth, C. (2013). "Challenges to BIM-cloud integration: Implication of security issues on secure collaboration." IEEE International Conference on Cloud Computing Technology and Science, pp.209-214.

McAdam, B. (2010). "Building information modelling: the UK legal context." International Journal of Law in the Built Environment, Vol.2, No. 3, pp. 246 - 259.

McCombs, M. and Reynolds, A (2002). News Influence on Our Pictures of the World. In J. Bryant, \& D. Zillmann (Eds.), Media Effects: Advances in Theory and Research (2nd ed., pp. 1-18). Mahwah: LEA.

Meijer, M. M. and Kleinnijenhuis, J. (2006). "Issue news and corporate reputation: Applying the theories of agenda setting and issue ownership in the field of business communication.” Journal of Communication, Vol. 56, No. 3, pp.543-559. 
Olatunji, O.A. (2011). A Preliminary Review on the Legal Implications of BIM and Model Ownership. Journal of Information Technology in Construction. Vol. 16, pp. 687-696.

Pishdad-Bozorgi, P., Austin, R.B. and de la Garza, J.M. (2016). "Network Analysis of FlashTrack Practices.” Journal of Management in Engineering, p.04016024.

Redmond, A., Hore, A. V. and West, R. (2010). "Developing a cloud integrated life cycle costing analysis model through BIM.” CIB W78 2011: Computer Knowledge Building, Sophia Antipolis - France.

Simonian, L. and Korman, T., (2010). "Legal Considerations in the United States Associated with Building Information Modeling." The Construction, Building and Real Estate Research Conference of the Royal Institution of Chartered Surveyors, RICS COBRA2010.

Smith, P. (2014). "BIM Implementation-Global Strategies." Creative Construction Conference, CC2014. Procedia Engineering. Vol. 85, pp. 482-492.

Solis, F., Sinfield, J.V. and Abraham, D.M. (2013). "Hybrid approach to the study of interorganization high performance teams." Journal of Construction Engineering and Management, Vol.139, No. 4, pp.379-392.

Steel, J., Drogemuller, R. and Toth, B. (2012). "Model interoperability in building information modelling.” Software \& Systems Modeling, Vol.11, No.1, pp.99-109.

Ussing, L. F., Svidt, K. and Wandahl, S. (2016). "Legal Aspects Connected to the Use of BIM in the Danish Building Sector." Construction Research Congress 2016, ASCE, pp. 528537.

Vu, H. N. N. and Gehrau, V. (2010). “Agenda diffusion: An integrated model of agenda setting and interpersonal communication." Journalism \& Mass Communication Quarterly, Vol. 87, No. 1, pp.100-116.

Wambeke, B.W., Liu, M. and Hsiang, S.M. (2014). “Task variation and the social network of construction trades." Journal of Management in Engineering, Vol. 30, No.4, 05014008. 